\title{
Acidemia metilmalónica: reporte de primer caso en México manejado con ácido carglúmico
}

\section{Methylmalonic acidemia: First case report in Mexico managed with carglumic acid}

\author{
Roberto Sandoval-Pacheco ${ }^{1 *}$, Ramón A. PÉrez-Martínez ${ }^{1}$ y Ramón MadRiz-Prado² \\ 'Unidad de Especialidades Médicas; ${ }^{2}$ Servicio de Pediatría. Hospital Militar de Especialidades de la Mujer y Neonatología, SEDENA, \\ Ciudad de México, México
}

\section{RESUMEN}

La acidemia metilmalónica es un trastorno metabólico considerado como una enfermedad rara (menos de 5 casos por 10,000 habitantes) incluido en el grupo de las acidemias orgánicas y que tiene una transmisión autosómica recesiva. Estas acidemias provocan episodios recurrentes de encefalopatía hiperamoniémica, debido a la alteración del ciclo de la urea, que en parte es la responsable del retraso cognitivo de los pacientes. El ácido carglúmico es un análogo sintético estable del NAG ( $N$-acetilglutamato), que puede estimular el primer paso del ciclo de la urea y de esta forma reducir los niveles de amoniaco en pacientes con hiperamoniemia secundaria, mejorando el cuadro clínico. Se presenta el caso de un varón con acidemia metilmalónica que fue tratado con ácido carglúmico.

Palabras clave: Acidemia metilmalónica. Hiperamoniemia. Ácido carglúmico.

\begin{abstract}
Methylmalonic acidemia is a rare metabolic disorder included in the group of organic acidemias and that has autosomal recessive transmission. These acidemias cause recurrent episodes of hyperammonemic encephalopathy, due to the alteration of the urea cycle, which is partly responsible for the cognitive delay of the patients. Carglumic acid is a stable synthetic analogue of NAG (N-acetylglutamate), which can stimulate the first step of the urea cycle and thus reduce ammonia levels in patients with secondary hyperammonemia, improving the clinical picture. The case of a baby with methylmalonic acidemia who was treated with carglumic acid is presented.
\end{abstract}

Key words: Methylmalonic acidemia. Hyperammonemia. Carglumic acid.
Correspondencia:

*Roberto Sandoval-Pacheco

E-mail: drsandovalpacheco@hotmail.com
Fecha de recepción: 18-06-2020

Fecha de aceptación: 27-10-2020 DOI: 10.24875/RME.20000065
Disponible en internet: 10-08-21 Rev Mex Endocrinol Metab Nutr. 2021;8:158-63

2462-4144 / @ 2020 Sociedad Mexicana de Nutricion y Endocrinologia, AC. Publicado por Permanyer. Este es un artículo open access bajo la licencia CC BY-NC-ND (http://creativecommons.org/licenses/by-nc-nd/4.0/). 


\section{INTRODUCCIÓN}

Las acidemias orgánicas (AO) son un grupo de trastornos metabólicos considerados como enfermedades raras (menos de 5 casos por 10,000 habitantes), que se transmiten de forma autosómica recesiva, observándose en recién nacidos o en bebés como descompensación metabólica aguda potencialmente mortal ${ }^{1,2}$. A pesar de que se han descrito más de $65 \mathrm{AO}$, las tres más frecuentes son la acidemia propiónica (AP), la acidemia metilmalónica (AMM) y la acidemia isovalérica ${ }^{1}$. Estas acidemias se caracterizan por episodios recurrentes de encefalopatía hiperamoniémica, que en parte es la causante del retraso cognitivo que afecta a estos pacientes ${ }^{3}$.

La AMM se produce por un defecto genético en la enzima metilmalonil-CoA mutasa (MUT) o en una de sus proteínas implicadas en la síntesis de su cofactor activo, la adenosil cobalamina ${ }^{1}$, lo que condiciona un incremento en los niveles de ácido metilmalónico en plasma y orina. Este incremento provocará alteraciones en el ciclo de la urea, produciendo finalmente hiperamoniemia ${ }^{3}$. Los pacientes con muto (pérdida completa de la actividad enzimática) o cblB (defecto de síntesis) tienden a estar más gravemente afectados que los pacientes con cblA (defecto de síntesis), o mut- (con actividad enzimática residual pero insuficiente ${ }^{4,5}$. La mayoría de las mutaciones se asocian al fenotipo mut0 y presentan mayores niveles de morbimortalidad 5 .

La prevalencia estimada de esta acidemia se sitúa en 1-9/100,000 recién nacidos vivos ${ }^{4}$.

Los signos clínicos incluyen letargo, retraso del crecimiento, vómitos recurrentes, deshidratación, insuficiencia respiratoria e hipotonía muscular, así como retraso del desarrollo neurosensorial, déficit intelectual y hepatomegalia, que aparecen a los 2-7 días del nacimiento' ${ }^{1}$. Si no se trata adecuadamente, producirá daño neurológico debido a un síndrome metabólico que afecta al tronco del encéfalo, con insuficiencia renal terminal, coma y muerte ${ }^{1}$.

La enfermedad puede responder o bien, ser resistente al tratamiento con vitamina $B_{12}$ (AMM sensible o resistente a vitamina $B_{12}$ ).

\section{PRESENTACIÓN DEL CASO}

Se presenta el caso de un paciente de sexo masculino de 3 años y 6 meses de edad, prematuro al nacer (33 semanas de gestación) por ruptura prematura de membranas. En el momento del nacimiento APGAR 5-7, se diagnosticó sepsis neonatal temprana y choque séptico (hiporreactividad a estímulos externos, hipotonía central, distensión abdominal, Silverman Anderson 5, temperatura $35.5^{\circ} \mathrm{C}$, llenado capilar de $4 \mathrm{~s}$, taquipnea $64 \mathrm{x}$, saturación de oxígeno del $88 \%$, proteína $\mathrm{C}$ reactiva $32, \mathrm{pH}$ del cordón 7.0 , presión parcial de dióxido de carbono $42 \mathrm{mmHg}$, bicarbonato $\left.\left[\mathrm{HCO}_{3}\right] 11 \mathrm{mmol} / \mathrm{l}\right)$, requiriendo orointubación durante dos semanas, así como las medidas habituales de manejo por los diagnósticos descritos. A los 21 días de vida se reporta tamiz neonatal con probable AP (reporte cualitativo de 3-hidroxipropionato y metilcitrato en orina).

En la historia familiar no existe endogamia ni consanguinidad y no se constataron enfermedades hereditarias ni otras patologías de interés.

Al mes de su nacimiento se realizó nuevo tamiz metabólico, con resultados negativos para acidemia orgánica. Se mantiene en vigilancia mensual por retraso global del neurodesarrollo con predominio en las áreas personal/social y lenguaje, además de pobre ganancia ponderal, sin más datos gastrointestinales o neurológicos.

Se realizó un tercer tamiz metabólico a los 9 meses de edad en el que se detectó elevación de ácido metilmalónico y trazas de metilcítrico. Los niveles de homocisteína fueron normales. Se inició tratamiento con carnitina $150 \mathrm{mg} / \mathrm{kg} / \mathrm{d}$ áa, biotina $10 \mathrm{mg} /$ día y vitamina $B_{12} 1,000 \mu \mathrm{g} /$ día. En ese control se constató persistencia del retraso del neurodesarrollo e hipoactividad, además de somnolencia. La analítica mostró niveles de amonio plasmático de $141 \mu \mathrm{mol} / \mathrm{l} ;$ acidosis metabólica: anion gap elevado (21), $\mathrm{pH} 7.31, \mathrm{HCO}_{3} 14$, lactato $3.8 \mathrm{mmol} / \mathrm{l}$, creatinina $0.6 \mathrm{mg} / \mathrm{dl}$, aspartato aminotransferasa $16 \mathrm{U} / \mathrm{l}$, alanina aminotransferasa $18 \mathrm{U} / \mathrm{l}$ : Se inicia restricción proteica ( $0.8 \mathrm{~g} / \mathrm{kg} / \mathrm{día}$ ) y aporte calórico de $110 \mathrm{kcal} / \mathrm{kg} /$ día a base de formula maternizada, dieta picada y medidas antiamonio de acuerdo con las guías de práctica 
Tabla 1. Evolución de los parámetros analíticos del paciente

\begin{tabular}{|c|c|c|c|c|c|c|}
\hline Parámetro & $\begin{array}{c}\text { Diagnóstico } 9 \\
\text { meses }\end{array}$ & 15 meses & 24 meses & $\begin{array}{l}2 \text { semanas de } \\
\text { tratamiento } \\
\text { con ácido } \\
\text { carglúmico: } \\
24 \text { meses }\end{array}$ & 3 años & $\begin{array}{l}3 \text { años } \\
6 \text { meses }\end{array}$ \\
\hline $\begin{array}{l}\text { Amonio plasmático } \\
\mu \mathrm{mol} / \mathrm{l}\end{array}$ & 141 & 52 & 124 & 23 & 15 & 21 \\
\hline Anion gap & 21 & 12 & 12 & 13 & 12 & 13 \\
\hline$\overline{\mathrm{pH}}$ & 7.31 & 7.37 & 7.37 & 7.36 & 7.38 & 7.37 \\
\hline $\mathrm{HCO}^{3}$ & 14 & 22 & 22 & 21 & 22 & 21 \\
\hline Lactato $\mathrm{mmol} / \mathrm{l}$ & 3.8 & 0.6 & 0.6 & 0.5 & 0.4 & 0.5 \\
\hline
\end{tabular}

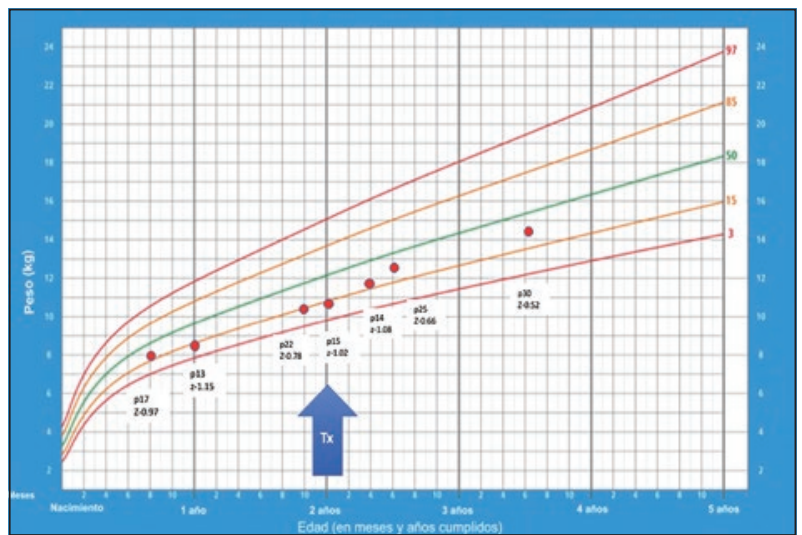

Figura 1. Peso para la edad, niños. Percentiles (nacimiento a 5 años).

clínica de Centro Nacional de Excelencia Tecnológica sobre el diagnóstico y tratamiento de la encefalopatía hepática 6 .

El amonio se redujo a $52 \mu \mathrm{mol} / \mathrm{l}$, con valores fluctuantes entre 52 y $121 \mu \mathrm{mol} / \mathrm{l}$ durante el manejo durante seis meses (Tabla 1).

A los 22 meses de edad fue valorado en el centro de rehabilitación infantil, donde se estableció un retraso del neurodesarrollo en áreas de lenguaje y personal/social (ocho y seis meses respectivamente).

Los padres refieren que el bebé tiene una importante somnolencia de hasta 16-18 horas de sueño/día aproximadamente (de las cuales $12-14 \mathrm{~h}$ de sueño nocturno y $4 \mathrm{~h}$ durante el día distribuidas en dos siestas) hasta los 2 años de edad.

A los 2 años de edad se inició tratamiento con ácido carglúmico ( $20 \mathrm{mg} / \mathrm{kg} /$ día), alcanzando en las primeras dos semanas de tratamiento niveles

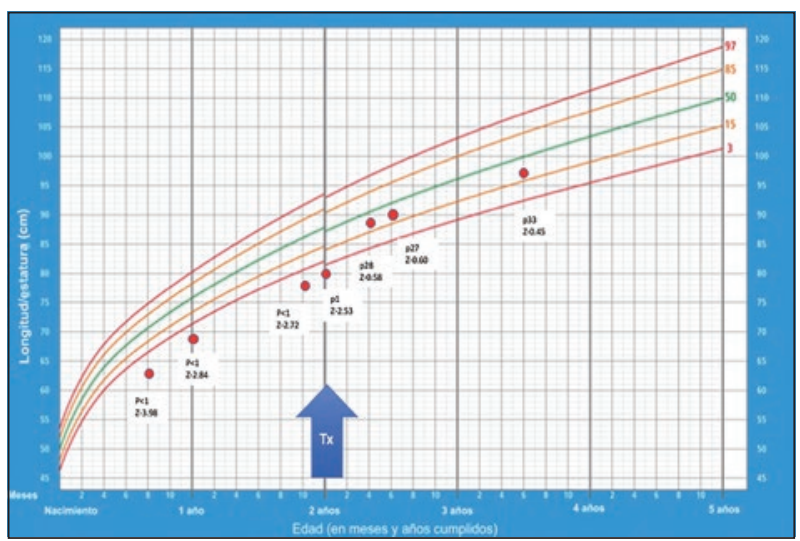

Figura 2. Longitud/estatura para la edad, niños. Percentiles (nacimiento a 5 años).

mantenidos de amonio entre 15 y $23 \mu \mathrm{mol} / \mathrm{l}$ e incrementando el aporte proteico a $1.2 \mathrm{~g} / \mathrm{kg} / \mathrm{dí}$. Con estas medidas se consiguió reducir el número de horas/sueño a $12 \mathrm{~h}$ nocturnas (sin siesta), además de mejoría de lenguaje.

Tras cuatro meses de tratamiento con ácido carglúmico se constató desarrollo personal/social adecuado para la edad. También se observó mejoría en la curva de evolución de la talla, que pasa de percentil 3 a percentil 25-50. A los seis meses la curva ponderal había mejorado del percentil 5 al percentil 25.

En el control correspondiente a los 3 años y 6 meses de edad el peso y la talla se mantuvieron en el percentil $25-50$ ( $14.4 \mathrm{~kg}$ y $95 \mathrm{~cm}$ respectivamente) (Figs. 1 y 2). En ese control, la concentración de amonio en sangre fue $51 \mu \mathrm{mol} / \mathrm{l}$, asociándose a cefalea y somnolencia, por lo que se incrementó la dosis de ácido carglúmico a 27.7 mg/kg/día. Se mantiene el 
tratamiento con biotina carnitina y vitamina $\mathrm{B}_{12}$, observando un neurodesarrollo normal para la edad.

\section{Estudio molecular}

Se realizó un estudio molecular consistente en exoma de genes asociados a AMM y AP (22 genes), así como otros genes involucrados en errores innatos del metabolismo (93 genes), encontrando solo una variante en estado heterocigoto probablemente patogénica en el gen del receptor de transcobalamina CD230 c.262_264GAG, que significa una deleción de los nucleótidos guanina-adenina-guanina, en el exón 2 del gen CD230. Esta alteración provoca una pérdida del aminoácido ácido glutámico en el receptor de transcobalamina en la posición 88 de la proteína ocasionando alteraciones en la función de esta que alteran la vía principal de la conversión de propionil-CoA en succinil-CoA. La enzima propionil-CoA carboxilasa dependiente de biotina convierte el propionil-CoA en D-metilmalonil-CoA, que luego se racemiza en L-metilmalonil-CoA y se isomeriza en succinil-CoA, un intermedio del ciclo de Krebs. La reacción de L-metilmalonil-CoA mutasa requiere de adenosilcobalamina, una forma activada de vitamina $B_{12}$. El receptor de transcobalamina es una proteína plasmática que se une a la vitamina $B_{12}$ (cobalamina) y facilita la absorción celular de cobalamina por la endocitosis mediada por el receptor, lo que afecta el procesamiento celular de la cobalamina $(\mathrm{OH}-\mathrm{Cbl})$ en la formación de adenosilcobalamina y metilcobalamina. La adenosilcobalamina es el cofactor de la reacción de metilmalonil-CoA mutasa; la metilcobalamina es el cofactor de la reacción de metionina sintasa, lo que ocasiona por lo tanto la aciduria metilmalónica y las alteraciones asociadas, como son elevación de homocisteína e hiperamonemia.

\section{DISCUSIÓN}

De acuerdo con la guía de práctica clínica de nuestro país el tratamiento debe incluir además de restricción proteica, carnitina, biotina, cianocobalamina, y medidas antiamonio; existen pacientes sensibles o respondedores a la vitamina $\mathrm{B}_{12^{\prime}}$ sin embargo, en nuestro caso el paciente se mantiene con niveles de amonio plasmático elevados y con pobre ganancia en peso y talla, lo que nos hace considerar que el paciente no es sensible a este manejo inicial.

El tratamiento con $\mathrm{N}$-carbamil-L-glutamato, un análogo sintético estable de NAG ( $\mathrm{N}$-acetilglutamato), el cofactor esencial de CPS-1 (carbamil fosfato sintetasa 1), puede estimular el primer paso del ciclo de la urea, permitiendo la formación de fosfato de carbamilo y reduciendo los niveles de amoniaco en pacientes con hiperamonemia secundaria ${ }^{1}$.

El manejo temprano con ácido carglúmico ha demostrado seguridad y eficacia a largo plazo en múltiples estudios a nivel internacional en el tratamiento de pacientes con diferentes padecimientos que condicionan hiperamonemia, entre ellos la deficiencia de NAGs ( $N$-acetil glutamato sintasa), las AO (metilmalónica, isovalérica y propiónica) y reportes aislados para hiperamonemia secundaria a insuficiencia hepática primaria o secundaria ${ }^{7}$.

El tratamiento convencional de la AMM incluye restricción proteica, fuente natural del amonio en plasma, lo que conlleva una ganancia ponderal no óptima en estos pacientes. El ácido carglúmico reduce los niveles de amonio actuando como restaurador de ureagénesis al activar la CPS17.

En nuestro paciente, la disminución de los niveles de amonio plasmáticos evidenció una mejoría significativa y a corto plazo en su desarrollo cognitivo, además de permitir un mayor aporte proteico, con lo que se logró alcanzar su peso y talla acorde a la edad en solo tres meses de tratamiento.

Las variantes patógenas en CD320 causan defectos en el receptor de transcobalamina, un error innato recientemente descubierto del metabolismo de la cobalamina. Solo se han reportado 12 casos hasta la fecha. Lo que llama la atención en el presente caso es que la mutación se encuentra en estado heterocigoto y la descripción de todos los casos hasta el momento están asociados con mutaciones en estado homocigoto como una enfermedad autosómico recesiva, por lo que, aunque el estudio no termina siendo concluyente, no debe dejarse de lado como una nueva forma de presentación autosómica dominante. 
Este caso con defecto del receptor de transcobalamina debido a variantes patogénicas en CD320 en estado heterocigoto amplía aún más nuestro conocimiento y proporciona un buen resultado tranquilizador a largo plazo para el desarrollo neurológico con tratamiento con cianocobalamina y para la hiperamonemia la utilización de ácido carglúmico, que ha demostrado en este paciente, como en otras enfermedades con hiperamonemia, la disminución de los niveles de amonio con buen resultado clínico. Además, podría recomendarse, para mayor abordaje molecular, la realización de estudios de MLPA (multiplex ligation-dependent probe amplification) para descartar grandes deleciones o duplicaciones que pasan desapercibidas en los estudios de exoma y de esta manera estar completamente seguros de que no se trata de heterocigoto compuesto con otro tipo de mutación en el otro alelo del mismo gen, o bien realizar estudio de medición del receptor de la transcobalamina para valorar el grado de deficiencia de esta.

Este resultado en el análisis molecular puede explicar la razón por la cual los primeros dos tamices metabólicos arrojaron resultados no concluyentes, ya que al tratarse de un paciente heterocigoto puede mantener una actividad enzimática residual en el gen no mutado que le permita no expresar un padecimiento con todas las características clínicas de gravedad y de laboratorio propias de pacientes homocigotos.

\section{CONCLUSIONES}

El ácido carglúmico resulta una terapia segura y eficaz para el manejo de pacientes con hiperamonemia secundaria a AMM.

La reducción en los niveles plasmáticos de amonio permitió, por un lado, mejorar el patrón de ciclo sueño/vigilia, aumentando la velocidad para la adquisición de los hitos del desarrollo, y por otro incrementando la ingesta de proteínas con la ganancia ponderal consecuente.

El tratarse de un caso con variante heterocigota nos puede explicar la excelente evolución al manejo establecido y a la dificultad diagnóstica después de tres tamices realizados.

\section{PERSPECTIVAS Y RECOMENDACIONES}

La historia natural de las AO conlleva una morbimortalidad significativa en los pacientes que la aquejan, por lo que la utilización de nuevos esquemas de tratamiento disponibles debe ser considerado de forma temprana al confirmar su diagnóstico. Se sugiere, ante la respuesta observada en nuestro paciente, que el ácido carglúmico sea iniciado una vez que se cuente con un diagnóstico confirmado de hipermoniemia de diferentes causas al mostrar un perfil de seguridad, tolerancia y eficacia adecuados.

\section{FINANCIAMIENTO}

Recibimos apoyo para el análisis molecular por parte de Recordati Rare Diseases y Oncomedic distribuidora de medicamentos S.A. de C.V.

\section{CONFLICTO DE INTERESES}

Los autores declaran no tener conflicto de intereses.

\section{RESPONSABILIDADES ÉTICAS}

Protección de personas y animales. Los autores declaran que para esta investigación no se han realizado experimentos en seres humanos ni en animales.

Confidencialidad de los datos. Los autores declaran que han seguido los protocolos de su centro de trabajo sobre la publicación de datos de pacientes.

Derecho a la privacidad y consentimiento informado. Los autores han obtenido el consentimiento 
informado de los pacientes y/o sujetos referidos en el artículo.

\section{BIBLIOGRAFÍA}

1. Häberle J, Chakrapani A, Ah Mew N, Longo N. Hyperammonaemia in classic organic acidaemias: A review of the literature and two case histories. Orphanet J Rare Dis. 2018;13(1):219.

2. Baumgartner MR, Hörster F, Dionisi-Vici C, Haliloglu G, Karall D, Chapman KA, et al. Proposed Guidelines for the Diagnosis and Management of Methylmalonic and Propionic Acidemia. Orphanet J Rare Dis. 2014;9:130.

3. Nashabat M, Obaid A, Al Mutairi F, Saleh M, Elamin M, Ahmed H, et al. Evaluation of long-term effectiveness of the use of carglumic acid in patients with propionic acidemia (PA) or methylmalonic acidemia (MMA): Study protocol for a randomized controlled trial. BMC Pediatr. 2019;19(1):195.

4. El portal sobre enfermedades raras y medicamentos huérfanos [Internet]. Orphanet [último acceso: junio 2020]. Disponible en: https://www. orpha.net/consor/cgi-bin/index.php?lng=ES

5. Chu $\mathrm{TH}_{1}$ Chien $\mathrm{YH}_{\text {, Lin }} \mathrm{HY}$, Liao $\mathrm{HC}$, $\mathrm{Ho} \mathrm{HJ}$ Lai $\mathrm{CJ}$, et al Methylmalonic acidemia/propionic acidemia - the biochemical presentation and comparing the outcome between liver transplantation versus non-liver transplantation groups. Orphanet J Rare Dis. 2019;14(1):73.

6. Guía de Práctica Clínica Diagnóstico y Tratamiento de Encefalopatía Hepática en el Adulto [Internet]. México: Secretaría de Salud, CENETEC; 2013 [último acceso: junio 2020]. Disponible en: https://www.academia. edu/31686508/encefalopatia hepatica

7. Pintos Morell G, Vilaseca Busca MA, Briones Godino P, Sanjurjo Crespo P. Trastornos del ciclo de la urea. Protocolo de diagnóstico y tratamiento de los trastornos del ciclo de la urea 2011 [Internet]. Asociación Española Para el Estudio de los Errores Congénitos del Metabolismo [último acceso: junio 2020]. Disponible en: http://www.ae3com.eu/protocolos/ protocolo1.pdf 